\title{
Adhesion of HVOF-Sprayed WC-Co Coatings on 316L Substrates Processed by SLM
}

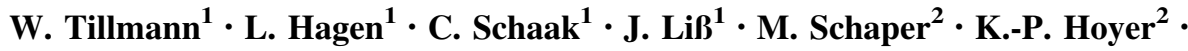 \\ M. E. Aydinöz $z^{2}$ K.-U. Garthe ${ }^{2}$
}

Submitted: 15 November 2019/in revised form: 19 June 2020/Published online: 7 August 2020

(C) The Author(s) 2020

\begin{abstract}
Different studies have been demonstrated that the surface integrity of substrate bulk materials to be coated has a significant impact on the adhesion of thermally sprayed coatings. It is known that the surface integrity of parts processed by selective laser melting (SLM) differs from those obtained from bulk materials. Although $316 \mathrm{~L}$ stainless steel is among the most investigated material for SLM, the adhesion of thermally sprayed coatings on $316 \mathrm{~L}$ stainless steel substrates processed by SLM has not been studied yet. This study aims at evaluating the effect of various mechanical pre-treatments onto $316 \mathrm{~L}$ stainless steel substrates processed by SLM and their effect on the adhesion of high velocity oxy-fuel (HVOF)-sprayed WCCo coatings. To differentiate between topographical effects and residual stress-related phenomena, a stress-relief heat treatment of the SLM substrates served as a reference throughout the investigations. The differently pre-treated SLM substrates were investigated with regard to the surface roughness and residual stresses. For the HVOFsprayed SLM composites, Vickers interfacial indentation tests were conducted to assess the resulting coating
\end{abstract}

Production Notes: Residual Stresses Credit Line: This article is part of a special topical focus in the Journal of Thermal Spray Technology on Advanced Residual Stress Analysis in Thermal Spray and Cold Spray Processes. This issue was organized by Dr. Vladimir Luzin,

Australian Centre for Neutron Scattering; Dr. Seiji Kuroda, National Institute of Materials Science; Dr. Shuo Yin, Trinity College Dublin; and Dr. Andrew Ang, Swinburne University of Technology.

L. Hagen

leif.hagen@udo.edu

1 Institute of Materials Engineering, TU Dortmund University, Dortmund, Germany

2 Chair of Materials Science, Paderborn University, Paderborn, Germany adhesion. The findings demonstrated that the HVOFsprayed WC-Co coatings predominantly exhibit good adhesion to the SLM 316L substrates. However, it was found that the stress state in the SLM 316L substrate surface is more likely to affect the adhesion of the WC-Co coating, while the substrate surface roughness showed a marginal effect.

Keywords $316 \mathrm{~L} \cdot \mathrm{HVOF} \cdot$ selective laser melting $\cdot$ WCCo coatings

\section{Introduction}

Currently, scarce raw material resources, high $\mathrm{CO}_{2}$ emissions, stricter environmental regulations, as well as the reduction in energy costs are of great interest. Thus, the demand for future-oriented and economical manufacturing processes continues to increase. Regarding the production of one-off prototypes or parts (i.e., in small batches), and complex components, additive manufacturing processes are more than ever in the focus of interest. This is caused by the demand for a high degree of design freedom concerning the component geometry, combined with short production times. SLM (tradename of SLM Solutions Group AG) is one of the most common processes in the field of additive manufacturing (Ref 1) and widely used term or synonym for laser beam melting. Due to the inherent process characteristics (Ref 2), the produced samples still exhibit a residual porosity and high surface roughness. The resulting microstructural characteristics (e.g., grain orientation) and residual stresses (Ref 3), among others, depend on the thermal history during processing, which in turn is associated with the building strategy. 
316L stainless steel provides outstanding mechanical properties as well as good corrosion resistance (Ref 4). The material is predominantly used in the oil and gas industry, chemical industry, the aerospace, and automotive industries, as well as for surgical instruments $(\operatorname{Ref} 4,5)$. Additionally, 316L has a good weldability (Ref 6) and therefore ideally suited for additive manufacturing. The microstructural characteristics of $316 \mathrm{~L}$ parts, produced by SLM, differ from those obtained from bulk materials (Ref 7). 316L parts processed by SLM are commonly characterized by a fine-grained, irregular microstructure with grains arranged along the building direction, which lead to an anisotropy of mechanical properties. Despite the porosity in additively manufactured 316L steel, the produced material possesses high strength and good ductility (Ref 8).

It is known that the fatigue strength of SLM parts is reduced by process-related restrictions such as high surface roughness and residual stresses, i.e., tensile residual stresses. The introduction of tensile residual stresses can cause cracking and fatigue failure if their magnitude exceeds the yield strength of the material. In contrast, compressive residual stresses in SLM parts (e.g., in the outer surface) can lead to an increased fatigue strength. According to the origin of residual stresses in SLM, thermal stresses constitute a major portion and are caused by large temperature gradients during melting and shrinkage throughout solidification of the molten baths (Ref 3,9). The final residual stress is further affected by the simultaneous remelting of the already solidified layer below during the fabrication of the overlying layer (melt-back) (Ref 10). Hence, the generation of residual stresses during SLM can be attributed to the temperature gradient mechanism and cool-down mechanism (Ref 11). Based on the thermal history in SLM, the outer layers feature higher temperatures than the underlying layers. The metallurgical bond between the respective outer and underlying layers hinders the expansion of the hotter layers, which in turn favors the emergence of tensile residual stresses in the respective outer layers and generates lower compressive residual stresses in the underlying layers (Ref 11). These relationships have been recently demonstrated for $316 \mathrm{~L}$ parts processed by SLM (Ref 9, 10). Furthermore, Simson et al. (Ref 9) showed that the building strategy in SLM gives rise to an anisotropy in the resulting residual stress distribution. Thus, for the outer surface, the authors evaluated increased in-plane residual stresses in the direction of assembly, i.e., building direction and thus perpendicular to the exposure direction. In this respect, SLM parts commonly undergo a subsequent heat treatment (e.g., stress-relief heat treatment (SRT) (Ref 12) and solution annealing (Ref 13)), whereby the microstructure is homogenized (Ref 10). As a result, the residual stresses can be reduced significantly. Reimer et al. (Ref 12) demonstrated that tensile residual stresses in
316L SLM parts can be halved by using a SRT. Löber et al. (Ref 14) compared different post-processing techniques such as grinding, or grit blasting and evaluated their effectiveness and applicability for improving the surface roughness of SLM processed $316 \mathrm{~L}$ parts. The authors emphasized the effectiveness of a subsequent grinding process to smooth the surface, but stated that grit blasting provides a greater flexibility than grinding (e.g., for complex geometries), since the latter is limited by the work piece accessibility. Nonetheless, further microstructural investigations are not indicated by the authors. In contrast, Li et al. (Ref 10) reported that a subsequent grinding process on the surfaces of SLM parts can be used to superimpose the tensile residual stress, i.e., the inherent stress state onto the surface, with compressive residual stresses.

Most components for industrial applications produced by SLM are intended for the usage under high mechanical, thermal, or corrosive loads. Surface functionalization by means of thermal spraying offers the opportunity to further enhance the performance of the entire component, i.e., the coated SLM substrate. For instance, with regard to tribologically stressed surfaces, the deposition of thermally sprayed hard coatings onto steel substrates can improve the wear resistance and thus increase the durability. For SLM substrates, the resulting surface roughness and the residual stresses are of crucial importance for further post-processes such as thermal spraying, i.e., to achieve an adequate coating adhesion. With regard to a subsequent coating deposition using thin film technologies (e.g., physical or chemical vapor deposition), a smooth substrate surface finishing is required (Ref 15, 16), enabling an appropriate coating growth and a reduced risk of coating defects. In contrast, as discussed in (Ref 17), the initial surface roughness of SLM substrates might be beneficial concerning the adhesion of thermally sprayed coatings. In this respect, only very few studies have focused on the surface integrity of SLM substrates and its influence on the adhesion of thermally sprayed coatings. Zhang et al. (Ref 18) studied the deposition of alumina coatings onto 316L SLM substrates by means of atmospheric plasma spraying without the use of a substrate pre-treatment. Instead, the asbuilt surface of the SLM substrate was coated. The authors clarified that the adhesion of the alumina coating depends significantly on the SLM substrate surface morphology (in correspondence with the building direction), showing an increased bond strength of the alumina coating deposited on the vertical surface of the SLM substrate. As verified by cross-sectional analyses, the improved adhesion could be traced back to necking structures, semi-molten particles, and undercuts on the surface of the SLM substrate, which were completely covered by the alumina coating. In contrast, Tillmann et al. (Ref 17) stated that unmelted, poorly 
bonded particles at the surface of an IN718 SLM substrate increase the risk of crack initiation under load and therefore promote the traversing of cracks at the interface between the IN718 substrate and the atmospheric plasma sprayed as well as the HVOF-sprayed Ni20Cr deposit.

The deposition of WC-Co coatings by means of HVOF spraying has become an established approach in the field of surface engineering to protect tribologically stressed surfaces against wear. The generation of residual stresses in HVOF-sprayed WC-Co coatings is, among others, of decisive importance for the initiation and propagation of cracks in the coating or along the coating-substrate interface. The origin of residual stresses in HVOF-sprayed WCCo coatings has been comprehensively discussed, with quenching stresses, thermal stresses, phase transformation processes, and peening stresses caused by the kinetic energy of the impinging particles being reported as major sources (Ref 19, 20). For HVOF-sprayed hard coatings, Araujo et al. (Ref 21) stated that the stress gradient at the coating-substrate interface, and thus the superposition of the imposed residual stress on the existing residual stress should be considered when interpretating the coating adhesion. The authors reported that improved coating adhesion can be achieved through a reduced stress gradient at the coating-substrate interface. On the contrary, a distinct gradient acts as driving force for coating delamination. Wang et al. (Ref 22) studied the adhesion of WC-Co coatings on various steel substrate surface finishes obtained from grinding and grit blasting, clarifying that the coating adhesion also depends on the substrate roughness. The authors ascertained that a higher bond strength can be achieved with a higher surface roughness. For both processes (i.e., grinding and grit blasting), the abrasive particle size affects the resulting roughness significantly. Simultaneously, these processes contribute to an additional insertion of residual stresses into the substrate surface (Ref $23,24)$.

\section{Experimental}

\section{Additively Manufactured 316L Substrates}

The additively manufactured substrates were generated from a gas atomized austenitic high chromium steel (AISI 316L) powder (SLM Solutions, Germany) by means of SLM. As verified by laser diffraction analysis (Mastersizer 2000, Malvern Panalytical, Germany), the 50th percentile in diameter (D50) of the volumetric particle size distribution was $32.0 \mu \mathrm{m}$, whereas D10 and D90 were 16.2 and $57.8 \mu \mathrm{m}$. Within this study, a 250 HL SLM machine (SLM Solutions, Germany) was used to produce dog-bone-shaped low cycle fatigue (LCF) samples. The nominal gage length of the samples was $8 \mathrm{~mm} \times 3 \mathrm{~mm} \times 2.5 \mathrm{~mm}$. Table 1 summarizes the SLM process parameters used in this study. All samples were produced under argon atmosphere. The building direction was vertical using the skin-core strategy. To enhance the bond between the skin and core area, a beam off-set (compensation) was applied for the contour. The chemical composition of the 316L SLM substrates was verified by x-ray fluorescence analyses (Revierlabor, Germany) as well as the microstructural characteristics were evaluated by means of optical microscopy (microscope BX51M, Olympus, Japan) and X-ray microcomputed tomography (Xradia 520 Versa, Zeiss, Germany).

The additively manufactured $316 \mathrm{~L}$ substrates were subsequently subjected to two different surface treatments: (1) grit blasting and (2) grinding (Table 2). For the grit blasting, various grit sizes, i.e., within a range of F40 ( $440 \mu \mathrm{m}$ ) to F240 ( $45 \mu \mathrm{m}$ ), according to the Federation of European Producers of Abrasives (FEPA) (Ref 25), were utilized. Regarding the grinding process, various steps, including different abrasive particle sizes, were employed in order to obtain different surface finishes. Referring to "P80" (Table 2), a grit size of P80 ( $200 \mu \mathrm{m}$ ) according to FEPA was used. With respect to "P600," the sequence of steps was P80, P180 ( $82 \mu \mathrm{m})$, P320 ( $46 \mu \mathrm{m})$, and P600 ( $25 \mu \mathrm{m})$, whereas the grit sizes P80, P180, P320, P600, P800 ( $21 \mu \mathrm{m})$, P1200 $(\sim 15 \mu \mathrm{m})$, and P2500 $(\sim 8 \mu \mathrm{m})$ were used for the sample type "P2500." An additively manufactured 316L sample in its initial state (as-built) served as a reference. To distinguish between topographical and mechanical causes (i.e., residual stresses) and their effect on the coating adhesion, a SRT was conducted in a second measurement series (Table 2). The SRT was executed at $650{ }^{\circ} \mathrm{C}$ with a heating rate of $5.4{ }^{\circ} \mathrm{C} / \mathrm{min}$ and a holding time of $120 \mathrm{~min}$ according to a study by Riemer et al. (Ref 12), using a high-temperature vacuum oven (U 80/1H, Schmetz, Germany). The process as well as the subsequent furnace cooling was carried out in vacuum. Prior to the coating deposition, the $316 \mathrm{~L}$ substrate surfaces were examined by means of 3D profilometry using the optical microscope with focus variation Infinite Focus (Alicona, Austria), as well as the white light confocal microscope $\mu$ Surf

Table 1 SLM process parameters used in this study

\begin{tabular}{lcc}
\hline Process parameter & \multicolumn{2}{c}{ Local strategy } \\
\cline { 2 - 3 } & Volume contour & Volume area \\
\hline Laser power, $\mathrm{W}$ & 100 & 175 \\
Laser scanning speed, mm/s & 565 & 750 \\
Hatch distance, $\mathrm{mm}$ & & 0.12 \\
Layer thickness, $\mu \mathrm{m}$ & 30 & 30 \\
\hline
\end{tabular}


Table 2 Summary of the different sample treatments (pre-treatment and subsequent coating process)

\begin{tabular}{|c|c|c|c|c|c|c|c|c|}
\hline \multicolumn{3}{|c|}{ Grinding } & \multicolumn{3}{|c|}{ Grit blasting } & \multirow[t]{2}{*}{ SRT } & \multirow[t]{2}{*}{ HVOF } & \multirow[t]{2}{*}{ Labeling } \\
\hline P80 & P600 & $\mathrm{P} 2500$ & $\mathrm{~F} 40$ & F100 & $\mathrm{F} 240$ & & & \\
\hline \multicolumn{9}{|c|}{$316 L$ samples $(A S=$ as-built $)$} \\
\hline- & - & - & - & - & - & - & $x$ & AS (as-built) \\
\hline- & - & - & $\times$ & - & - & - & $\times$ & $\mathrm{F} 40$ \\
\hline- & - & - & - & $x$ & - & - & $x$ & F100 \\
\hline- & - & - & - & - & $x$ & - & $\times$ & $\mathrm{F} 240$ \\
\hline$x$ & - & - & - & - & - & - & $\times$ & P80 \\
\hline- & $\times$ & - & - & - & - & - & $\times$ & P600 \\
\hline- & - & $x$ & - & - & - & - & $\times$ & $\mathrm{P} 2500$ \\
\hline- & - & - & - & - & - & $x$ & $x$ & AS/SRT (stress-relief heat treatment) \\
\hline- & - & - & $\times$ & - & - & $x$ & $x$ & F40/SRT \\
\hline- & - & - & - & $\times$ & - & $x$ & $x$ & F100/SRT \\
\hline- & - & - & - & - & $\times$ & $\times$ & $x$ & F240/SRT \\
\hline$x$ & - & - & - & - & - & $x$ & $\times$ & P80/SRT \\
\hline- & $x$ & - & - & - & - & $x$ & $x$ & P600/SRT \\
\hline- & - & $x$ & - & - & - & $x$ & $\times$ & $\mathrm{P} 2500 / \mathrm{SRT}$ \\
\hline
\end{tabular}

(Nanofocus, Germany). The mean roughness Ra and mean roughness depth $\mathrm{Rz}$ were obtained from the extracted $3 \mathrm{D}$ morphologies. The residual stresses at the surface of the differently pre-treated $316 \mathrm{~L}$ substrates were investigated by means of $\mathrm{x}$-ray diffraction (XRD) analyses, employing the $\sin ^{2} \psi$ method (Ref 26, 27). The experiments were conducted using a Bruker Advanced D8 diffractometer (Bruker, Massachusetts, U.S.) with a $\mathrm{Cr} \mathrm{K} \alpha$ radiation $(\lambda=0.22910 \mathrm{~nm})$. Within the scope of this study, the austenitic $\gamma$-phase (220) reflection was considered. Thus, the (220) reflection in an angular range of $2 \Theta=126.5^{\circ}$ $131^{\circ}$ was investigated. The step width and exposure time were, respectively, $0.1^{\circ}$ and $2.5 \mathrm{~s}$ for each step. The measurement was performed for various tilt angles $\psi= \pm(0$; $7 ; 14 ; 21 ; 28 ; 35 ; 42 ; 49)$, and rotation angles $\varphi= \pm(0$; 180). A biaxial stress state was neglected due to the fact that the surface of the additively manufactured $316 \mathrm{~L}$ is randomly treated (i.e., plastically deformed) by the different mechanical surface treatments. The $d-\psi$ data were analyzed using the software of Leptos (Bruker, Massachusetts, U.S.). In this context, a Young's modulus, $E$, of $207 \mathrm{GPa}$ and a Poisson ratio, $v$, of 0.28 were used according to (Ref 28). The $\mathrm{x}$-ray elastic constants $\left(s_{1}=-1.353 \mathrm{E}-6 ; 1 / 2 \quad s_{2}=6.184 \mathrm{E}-6\right)$ were computed based on the Voigt model as described in (Ref 26, 27).

\section{Coating Deposition}

For depositing coating, a HVOF WokaJet 400 spraying system (Oerlikon Metco, Switzerland) equipped with a Oerlikon Metco MultiCoat controller system, and a Twin-
Table 3 Spray parameter settings

\begin{tabular}{llll}
\hline Oxygen flow, 1/min & 876 & Powder carrier gas, 1/min & $2 \times 4.6$ \\
Kerosene flow, 1/h & 23 & Feeding disk setting, \% & 20 \\
Spray distance, mm & 300 & Stirrer setting, \% & 50 \\
Overruns & 20 & & \\
\hline
\end{tabular}

120-H powder feeder was used. An agglomerated and sintered WC-Co powder (88 wt.\% WC and 12 wt.\% Co with a WC Fisher sub-sieve size (FSSS) of $2.5 \mu \mathrm{m}$, Woka 3102, Oerlikon Metco, Switzerland) with an agglomerate size fraction of $-45+15 \mu \mathrm{m}$ served as feedstock. The spray torch was mounted on an ABB IRB 4600 60/2.05 6-axis robot. The experiments were carried out on a turning lathe. To achieve an all-side coating, the different pretreated $316 \mathrm{~L}$ substrates (Table 2) were rotated using a rotating velocity of $600 \mathrm{rpm}$. Within all the coating experiments, a transverse speed of $130 \mathrm{~mm} / \mathrm{s}$ was applied for moving the spray torch over the sample. Each experiment was conducted with a front side cooling pressure of 40 psi. Table 3 shows the spray parameter settings which were kept constant for all experiments.

\section{Coating Adhesion}

Different studies showed the validity of using the interface toughness (i.e., a term representing the capacity to resist the initiation and propagation of a crack at the coatingsubstrate interface) to evaluate the coating adhesion (Ref 29, 30). Vickers interfacial indentation tests allow 
determining the interface toughness, hereinafter referred to as interfacial indentation toughness $\mathrm{Kca}$ (Ref 31). To assess the adhesion of the HVOF-sprayed WC-Co coatings to the additively manufactured $316 \mathrm{~L}$ substrate, Vickers interfacial indentation tests were conducted according to (Ref 32,33 ). Prior to the interfacial testing, cross sections were prepared by using diamond grinding disks and polishing cloths with a diamond suspension (particle sizes: 9, 6, 3, and $1 \mu \mathrm{m}$ ). The indents were applied at the interface under room temperature. Indentation loads were set to 2.94, 9.80, $29.42,294.21,490.35$, and $980.70 \mathrm{~N}$ with a dwell time of $60 \mathrm{~s}$ using the microhardness tester model Duramin-40 (Struers, Germany), and the universal hardness tester DIATESTOR 7521 (Wolpert, Germany). The resulting interfacial cracks were measured, as shown in (Ref 17), via image analysis with the use of a light microscope (microscope BX51M, Olympus, Japan). For each load, a minimum of six indents were taken. Six cross sections (i.e., out of three samples) for each surface condition (Table 2) were considered within the experimental study. The interfacial indentation toughness $\mathrm{Kca}$ was determined according to the empirical approach shown by Lesage and Chicot (Ref 34) (see Eq 1 and 2)

$$
\begin{aligned}
& K c a=0.015 \cdot \frac{P_{\mathrm{C}}}{a_{\mathrm{C}}^{3 / 2}} \cdot\left(\frac{E}{H}\right)_{i}^{1 / 2} \\
& (E / H)_{i}^{1 / 2}=\frac{(E / H)_{\mathrm{S}}^{1 / 2}}{1+\left(H_{\mathrm{S}} / H_{\mathrm{C}}\right)^{1 / 2}}+\frac{(E / H)_{\mathrm{C}}^{1 / 2}}{1+\left(H_{\mathrm{C}} / H_{\mathrm{S}}\right)^{1 / 2}}
\end{aligned}
$$

where $E_{\mathrm{S}}$ and $H_{\mathrm{S}}$ are the Young's modulus and hardness of the $316 \mathrm{~L}$ substrate. The indices $E_{\mathrm{C}}$ and $H_{\mathrm{C}}$ represent the Young's modulus and hardness of the HVOF-sprayed WCCo coating. The Young's modulus and hardness of the 316L substrate and WC-Co coating were determined by means of nanoindentation load-displacement curves, as demonstrated by Oliver and Pharr (Ref 35), utilizing the nanoindentor type G200 (Agilent Technology, USA). A total amount of 49 indents $(7 \times 7)$ were performed with a diamond Berkovich indenter in regular intervals at the cross section close and parallel to the coating-substrate interface in load-controlled mode at a load of $50 \mathrm{gf}$. To avoid a distortion of the mechanical testing results, the distance between the indents was set to be $50 \mu \mathrm{m}$. The residual indents were evaluated by light microscopy and assigned to individual regions of interest, i.e., the WC-Co coating, and the interface of the $316 \mathrm{~L}$ substrate. Accordingly, only indents in the immediate vicinity of the coatingsubstrate interface were used for the calculation. To compute the Young's modulus, a Poisson's ratio of 0.28 and 0.30 was utilized for the $316 \mathrm{~L}$ substrate, and the WC-Co coating, respectively. The interface roughness of the HVOF-sprayed SLM composites was analyzed via cross- sectional images. For this purpose, a series of light micrographs at $\times 1000$ magnification were recorded along the coating-substrate interface (or substrate surface for an uncoated reference) using the optical microscope BX51M (Olympus, Japan). The image composition was processed with the software Leica Map 8 using the contour analysis module (Leica microsystems, Switzerland). Discontinuities at interface profile, i.e., interfacial line, were cleaned by morphological operations. The interfacial roughness profile of the coating-substrate interface was extracted, and amplitude parameters such as $\mathrm{Rz}$ and $\mathrm{Ra}$ were determined according to DIN EN ISO 4287.

\section{Results and Discussion}

\section{Microstructural Characteristics of 316L Substrates}

Light micrographs of etched cross- (perpendicular to the building direction) and longitudinal-sections depict the occurrence of solidified melt pools and scan tracks dependent on the scanning strategy (Fig. 1). Individual layers were melted using an alternating bi-directional laser scanning and a $90^{\circ}$ scan rotation between successive layers, showing an alternating scan track orientation. By scanning the recently deposited metal powder, previously solidified layers will be re-melted which results in a good metallurgical bonding. It has frequently been shown experimentally and numerically that the depth of the weld pool is approximately $100 \mu \mathrm{m}$ to $150 \mu \mathrm{m}$. As verified by x-ray microcomputed tomography, the generated 316L samples possess an overall porosity of $0.160 \%$ (measured with a voxel edge length of $70 \mathrm{~nm}$ ), demonstrating a relative high density. Nevertheless, high-resolution tomograms (Fig. 2) reveal a greater amount of pores in the boundary region (between the shell and core region) as well as in the area near the surface. Accordingly, the sampling demonstrated a mean porosity of $0.289 \%$ in the area near the surface (including the boundary region), whereas the mean porosity was $0.004 \%$ in the center.

As indicated by x-ray fluorescence analysis (Table 4), the chemical composition of the specimens mainly corresponds with the nominal chemical composition of the feedstock.

As verified by XRD analysis (Fig. 3), a face-centered cubic (fcc), austenitic phase ( $\gamma$-phase) was found in both the pre-alloyed $316 \mathrm{~L}$ powder (feedstock) and $316 \mathrm{~L}$ substrates. Additionally, a preferred grain orientation in the (111) direction is observed, which can be explained by the scanning strategy. Liverani et al. (Ref 36) showed this dependence for additively manufactured $316 \mathrm{~L}$ samples processed by SLM. As indicated by small peak reflection at 
Fig. 1 Light micrographs of an etched (Kalling 2) 316L sample (as-built) showing the microstructure formation (a) at the longitudinal-section, and (b) at the cross-section. A magnified view of the microstructure at the cross section is shown in (c)
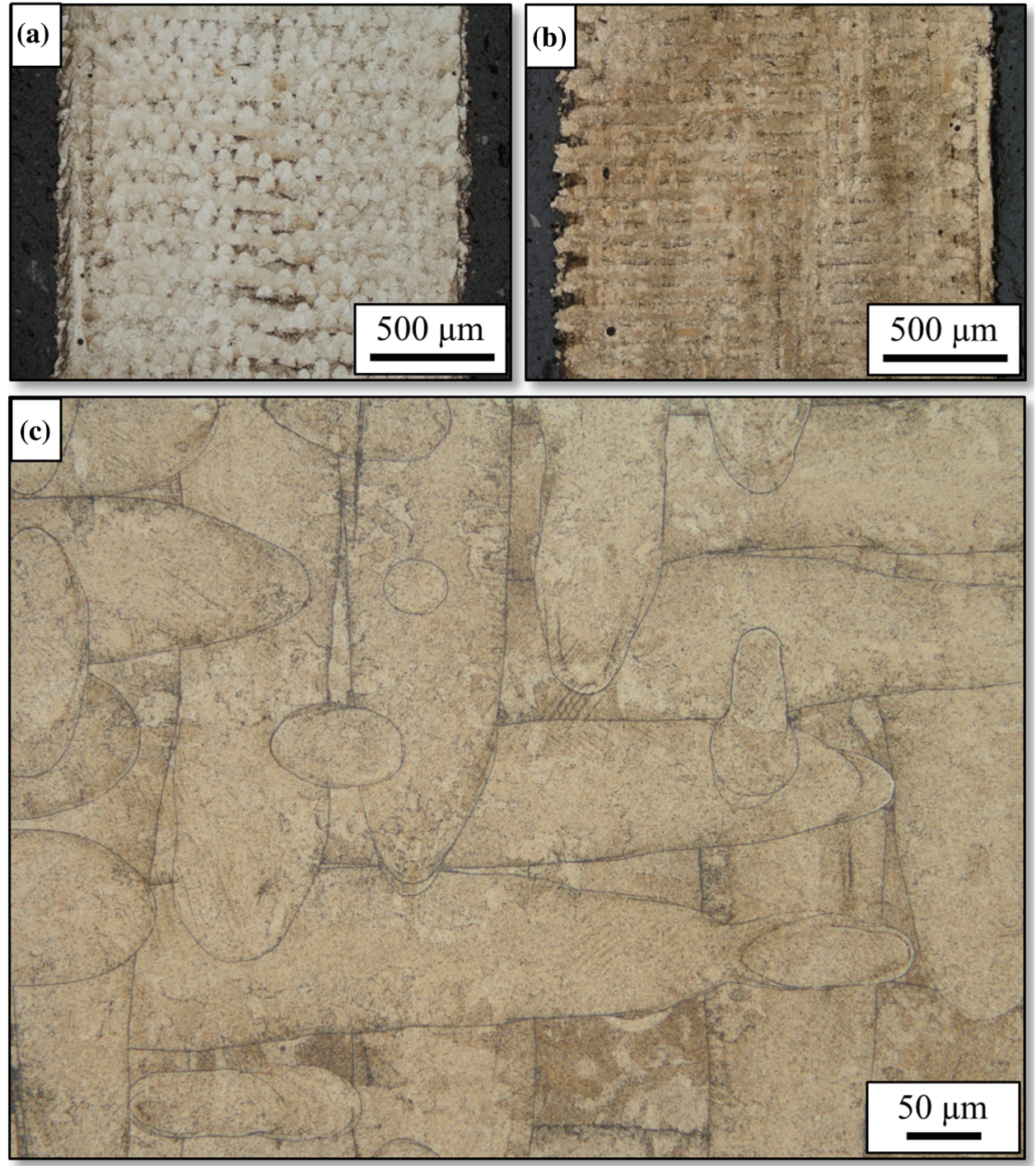

a diffraction angle $2 \theta$ of approximately $68^{\circ}$, it is stated that the $316 \mathrm{~L}$ powder consists of a small amount of the bodycentered cubic phase (ferritic phase). This phase partially converted into the $\gamma$-phase by remelting during SLM. However, due to the fast cooling rates during processing, it is stated that small amounts of the ferritic phase remain in the microstructure. Similar findings were observed by Saeidi et al. (Ref 37) and Sun et al. (Ref 38).

\section{Characterization of Pre-treated 316L Substrates}

The resulting surface roughness of the differently pretreated $316 \mathrm{~L}$ substrates as obtained from the $3 \mathrm{D}$ profilometry is summarized in Table 5. It can be seen that the resulting surface roughness is affected by the abrasive particle size (i.e., used for grit blasting, and grinding). Thus, a finer abrasive particle size leads to a smoother surface, which is particularly noticeable for the ground surfaces
(P80, P600, and P2500). Simultaneously, grinding results in a significantly lower surface roughness than grit blasting. The topography of the 316L SLM ground surfaces resembles the patterns of ground bulk materials. In terms of the grit-blasted samples, it is striking that the use of fine abrasive particles (sample F240: $\mathrm{Ra}=7.52 \pm 1.09 \mu \mathrm{m}$ ) leads to a higher surface roughness compared to the use of coarser abrasive particles (sample F40: $\mathrm{Ra}=7.12 \pm 0.78 \mu \mathrm{m}$; sample F100: $\mathrm{Ra}=6.09 \pm 1.08 \mu \mathrm{m})$. This is due to the fact that the fine abrasive particles remove the poorly bonded particles on the surface. As a result, undulating surface irregularities with some cavities remain. In contrast, the use of coarser abrasive particles leads to a greater plastic deformation. When compared to the as-built state (AS), the grit-blasted samples feature a reduced surface roughness. Similar findings are reported by Löber et al. (Ref 14).

Prior to the coating deposition, a second measurement series of $316 \mathrm{~L}$ substrates were subjected to an additional 
SRT (Table 2). The differently pre-treated 316L substrates were investigated by means of XRD (Fig. 4). When compared to the as-built state (sample AS), the XRD patterns obtained from the differently pre-treated samples verify the absence of phase transformation processes within the experimental resolution. Neither the mechanical pre-treatment nor the SRT lead to the formation of new phases. When compared to sample AS (or AS/SRT), the ground surfaces P80, P600, and P2500 (Fig. 4a) (or P80/SRT, P600/SRT P2500/SRT, Fig. 4b) reveal a preferred orientation or change in grain orientation along the (200) planes. Furthermore, the XRD patterns in Fig. 4(a) demonstrate a peak broadening for both the ground and the grit-blasted surfaces. Accordingly, the (111), (200), and (220) reflections for the ground surfaces (P80, P600, and P2500) exhibit an increased full width at half maximum (FWHM) of the diffraction peaks (Table 6) compared to the as-built sample (AS). This is more pronounced for the grit-blasted surfaces (F40, F100, and F240) and is all greater, the larger

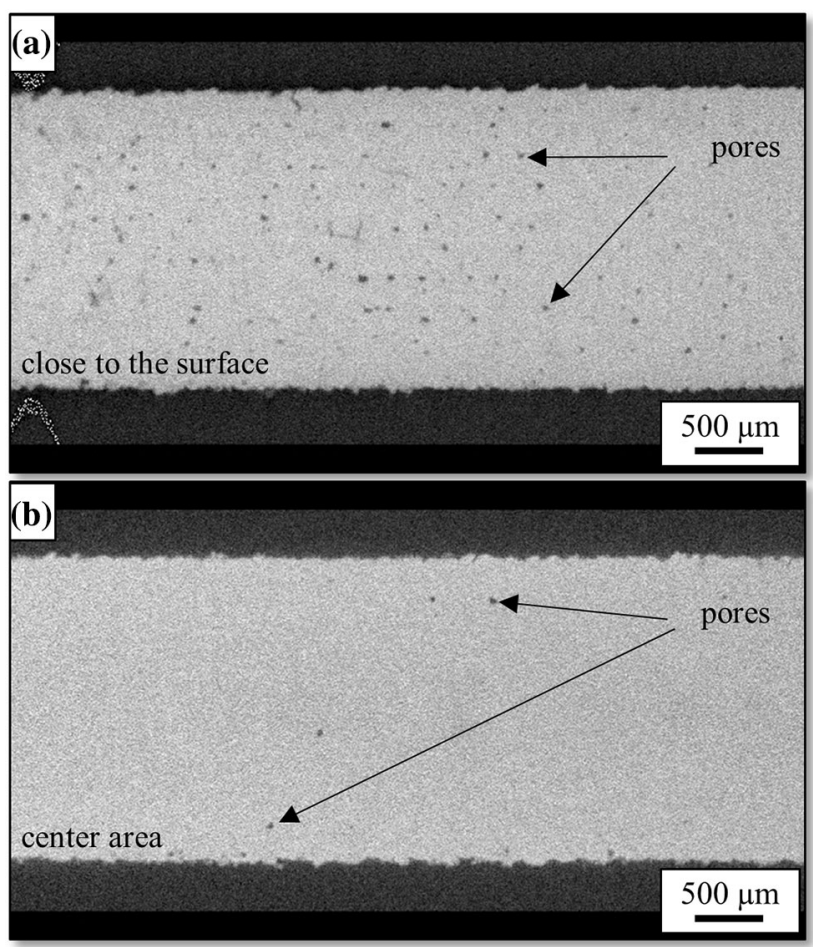

Fig. 2 Tomograms of the produced 316L sample showing (a) the longitudinal-section close to the surface, and (b) the longitudinalsection at the center area the abrasive particle size. It is stated that the peak broadening (i.e., the increase in FWHM) can be assigned to two effects: (1) the introduction of microstresses (residual stress of the second kind), and (2) grain refinement due to defects in the lattice structure. Both could be caused by plastic deformation during the mechanical processing. As obtained from the XRD patterns in Fig. 4(b), the SRT leads to a reduction in FWHM (Table 6), suggesting a reduction in microstresses or a change in crystallite size.

The residual stresses (first kind) at the surface of the differently pre-treated 316L substrates are presented in Fig. 5. It is found that the surface of the as-built sample (AS) exhibits tensile residual stresses of $79.1 \pm 19.8 \mathrm{MPa}$, whereas the ground surfaces (P80, P600, P2500) and gritblasted surfaces (F40, F100, F240) possess compressive residual stresses in different orders of magnitude (Fig. 5a). It is assumed that the compressive residual stresses are introduced into the surface due to plastic deformation, and thus superimpose the tensile stresses of the initial stress state. For the grit-blasted surfaces, it is noticeable that the final residual stresses obtained from sample F240 and F100 have roughly the same order of magnitude (F240: $\sigma=-363.6 \pm 16.8$ MPa; F100: $\sigma=-368.9 \pm 12.9 \mathrm{MPa})$. In contrast, the compressive residual stresses observed for sample F40 were less pronounced $(\sigma=-187.7 \pm 11.9 \mathrm{MPa})$. Since the compressive residual stresses in a grit-blasted surface should increase with increasing grit size due to the higher plastic deformation (Ref 39), this result has not yet been fully elucidated. With regard to the ground surfaces (P80, P600,

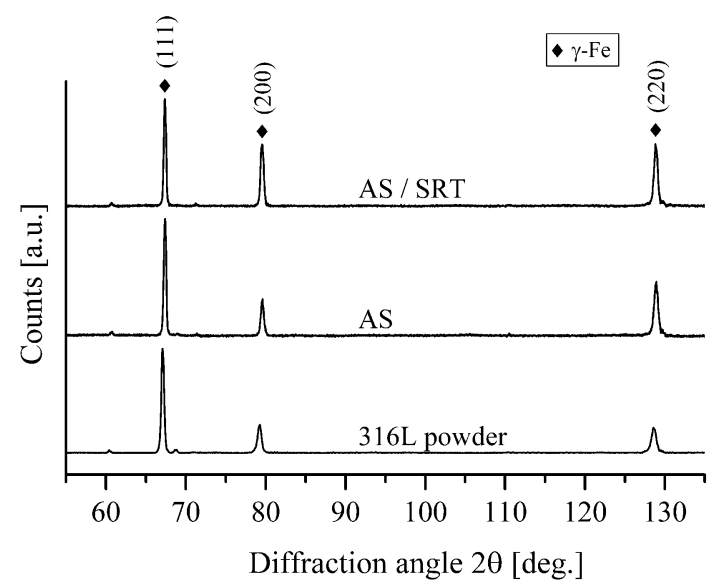

Fig. 3 XRD pattern observed for the 316L feedstock material and the 316L sample processed by SLM
Table 4 Chemical composition of the 316L feedstock and produced 316L SLM substrate

\begin{tabular}{lcccccccccccc}
\hline Sample & $\mathrm{O}$ & $\mathrm{Al}$ & $\mathrm{Si}$ & $\mathrm{Ti}$ & $\mathrm{Cr}$ & $\mathrm{Mn}$ & $\mathrm{Fe}$ & $\mathrm{Co}$ & $\mathrm{Ni}$ & $\mathrm{Cu}$ & $\mathrm{Mo}$ & Others \\
\hline SLM substrate & 0.07 & 0.11 & 0.51 & 0.05 & 17.1 & 1.00 & $\mathrm{Bal}$ & 0.05 & 11.5 & 0.12 & 2.29 & $<0.03$ \\
Feedstock & 0.05 & 0.05 & 0.78 & 0.03 & 16.9 & 1.40 & $\mathrm{Bal}$ & 0.03 & 11.5 & 0.04 & 2.39 & $<0.03$ \\
\hline
\end{tabular}

In wt. \% 
Table 5 Resulting surface roughness for differently pretreated $316 \mathrm{~L}$ substrates

\begin{tabular}{lcclll}
\hline Sample & $\mathrm{Ra}, \mu \mathrm{m}$ & $\mathrm{Rz}, \mu \mathrm{m}$ & \multicolumn{1}{c}{ Sample } & $\mathrm{Ra}, \mu \mathrm{m}$ & $\mathrm{Rz}, \mu \mathrm{m}$ \\
\hline AS & $9.77 \pm 0.97$ & $63.15 \pm 5.76$ & AS/SRT & $9.90 \pm 2.06$ & $66.13 \pm 15.73$ \\
F40 & $7.63 \pm 0.67$ & $46.09 \pm 4.41$ & F40/SRT & $6.62 \pm 0.90$ & $39.08 \pm 4.06$ \\
F100 & $6.68 \pm 0.84$ & $37.88 \pm 4.01$ & F100/SRT & $5.50 \pm 1.31$ & $31.35 \pm 4.75$ \\
F240 & $7.30 \pm 0.42$ & $43.54 \pm 3.01$ & F240/SRT & $7.75 \pm 1.77$ & $45.34 \pm 11.11$ \\
P80 & $0.28 \pm 0.03$ & $1.89 \pm 0.20$ & P80/SRT & $0.38 \pm 0.07$ & $2.42 \pm 0.35$ \\
P600 & $0.09 \pm 0.01$ & $0.73 \pm 0.09$ & P600/SRT & $0.10 \pm 0.02$ & $0.80 \pm 0.13$ \\
P2500 & $0.05 \pm 0.01$ & $0.37 \pm 0.07$ & P2500/SRT & $0.05 \pm 0.01$ & $0.36 \pm 0.04$ \\
\hline
\end{tabular}

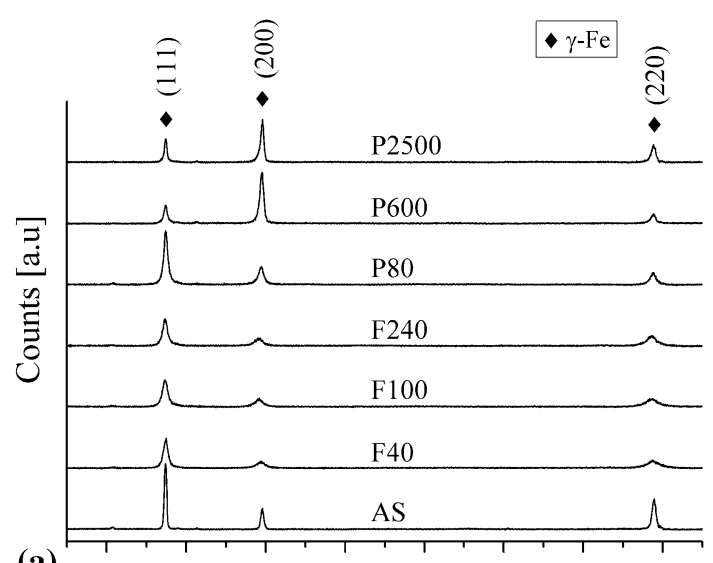

(a)

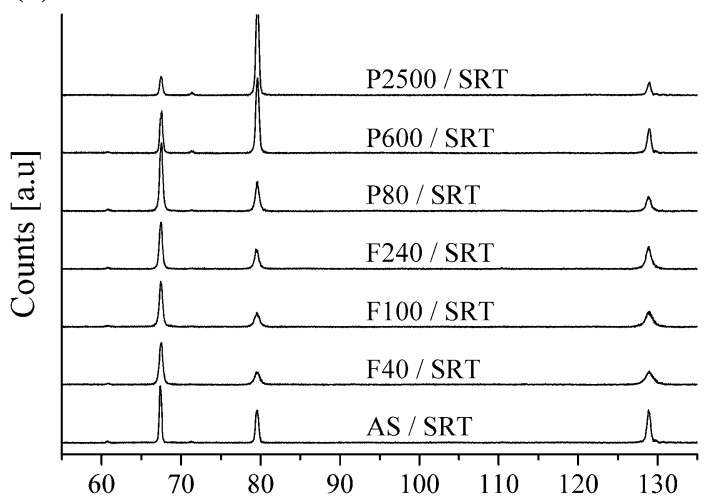

(b)

Diffraction angle $2 \theta$ [deg.]

Fig. 4 XRD patterns for the differently pre-treated 316L substrates: (a) non-heat-treated $316 \mathrm{~L}$ substrates, and (b) $316 \mathrm{~L}$ substrates processed by SRT; the samples AS and AS/SRT serve as reference

P2500), it can be seen that the compressive residual stresses diminish as the abrasive particle size decreases. As clarified in (Ref 40$)$, a coarser abrasive particle size leads to a greater deformation, whereby a higher amount of compressive residual stresses is introduced into the surface. Another approach could be a stronger superposition of tensile residual stresses, since the introduced stresses below the surface first increase in magnitude by the SLM process and then decrease toward the center of the SLM part (Ref 9). Since the sequence
Table 6 FWHM (full width at half maximum) of (111), (200), and (220) reflections obtained from the XRD pattern of differently pretreated $316 \mathrm{~L}$ substrates

\begin{tabular}{lccc}
\hline Labeling & $\begin{array}{c}\text { Peak (111) } \\
\text { FWHM, }\end{array}$ & $\begin{array}{c}\text { Peak (200) } \\
\text { FWHM, }\end{array}$ & $\begin{array}{r}\text { Peak (220) } \\
\text { FWHM, }\end{array}$ \\
\hline Feedstock & 0.4252 & 0.6020 & 0.7659 \\
AS & 0.3668 & 0.4754 & 0.6351 \\
F40 & 0.8157 & 1.4514 & 2.1614 \\
F100 & 0.9282 & 1.4084 & 2.0979 \\
F240 & 0.8532 & 1.3677 & 1.7222 \\
P80 & 0.7202 & 0.9343 & 1.0231 \\
P600 & 0.6391 & 0.6430 & 0.8697 \\
P2500 & 0.4427 & 0.5463 & 0.7566 \\
AS/SRT & 0.3511 & 0.4647 & 0.5739 \\
F40/SRT & 0.5548 & 0.8478 & 1.3250 \\
F100/SRT & 0.5419 & 0.8267 & 1.1855 \\
F240/SRT & 0.4911 & 0.6709 & 0.8833 \\
P80/SRT & 0.4918 & 0.6093 & 0.7485 \\
P600/SRT & 0.4405 & 0.4928 & 0.5901 \\
P2500/SRT & 0.4403 & 0.4631 & 0.5672 \\
\hline
\end{tabular}

The feedstock serves as reference

of grinding for P600 and P2500 was performed in several steps, both samples suffered a greater material removal, which releases larger tensile residual stresses with higher penetration depth (i.e., increasing depth path). Figure 5(b) shows the residual stresses at the surface of samples processed by an additional SRT. It is found that the SRT leads to a reduction in compressive residual stresses in the grit-blasted (F40/SRT, F100/SRT, F240/SRT) and ground surfaces (P80/SRT, P600/SRT, P2500/SRT). Nevertheless, some remaining residual stresses were not completely eliminated (e.g., AS versus AS/SRT). A measuring error of $40 \mathrm{MPa}$ was determined for a stress-relieved powder sample (i.e., polycrystalline $\mathrm{SiO}_{2}$ ). 

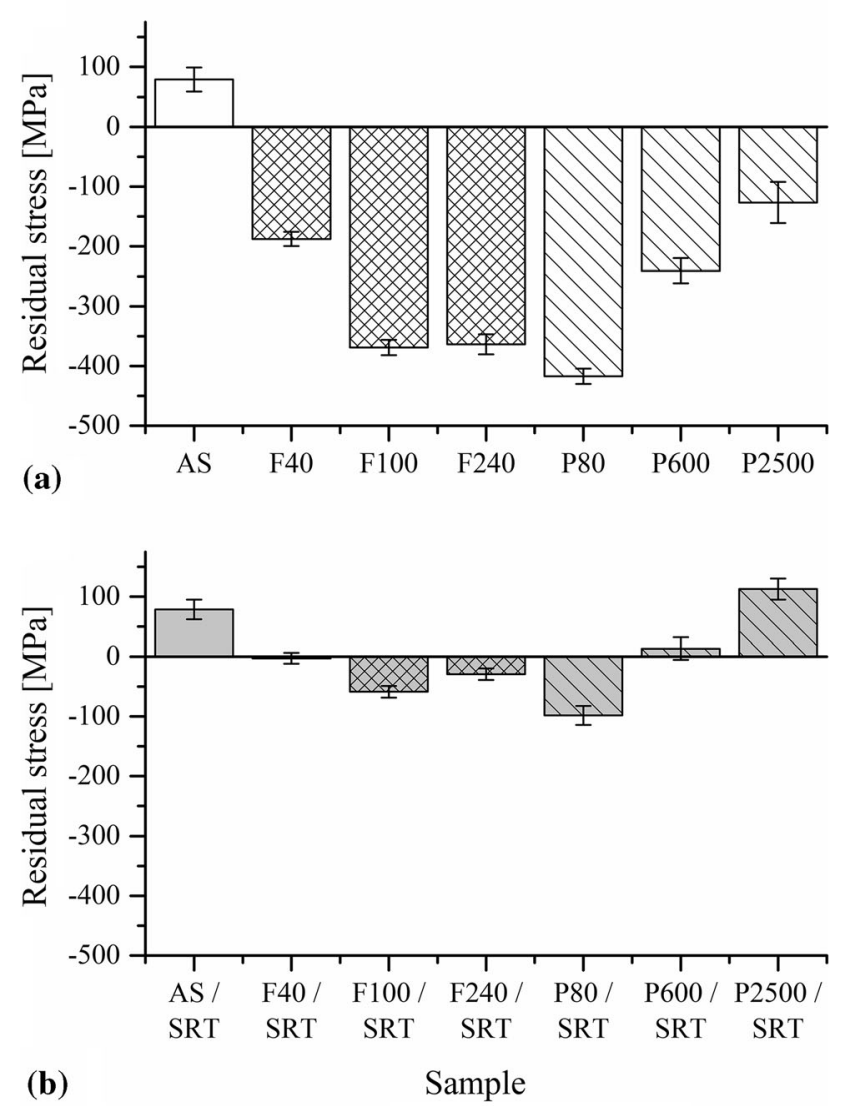

Fig. 5 Residual stresses measured at the surface of the differently pre-treated 316L substrates: (a) non-heat-treated 316L substrates, and (b) $316 \mathrm{~L}$ substrates processed by SRT; the samples AS and AS/SRT serve as reference

\section{Coating of 316L Substrates}

WC-Co coatings were successfully deposited onto SLM produced 316L substrates which either underwent different surface treatments (i.e., grinding, or grit blasting), or are used in their as-built state. Cross-sectional analyses confirm the absence of macroscopic defects such as cracks or delaminations, and the deposition of continuous coatings with a nearly constant coating thickness. For instance, Fig. 6 shows the cross section of a HVOF-sprayed WC-Co coating deposited onto a SLM manufactured $316 \mathrm{~L}$ substrate (i.e., sample F100). With regard to the $316 \mathrm{~L}$ substrate in its as-built state (sample AS), cross-sectional analysis reveals that globular-shaped particles are embedded in the coating next to the coating-substrate interface (Fig. 7). As verified by image analysis, the particle size corresponds to the nominal feedstock particle size. It is stated that unmelted individual particles, which are found to be present in the surface of the SLM substrate, get covered by the HVOF-sprayed WC-Co coating. It is striking that the protruding particles remain on the substrate surface,

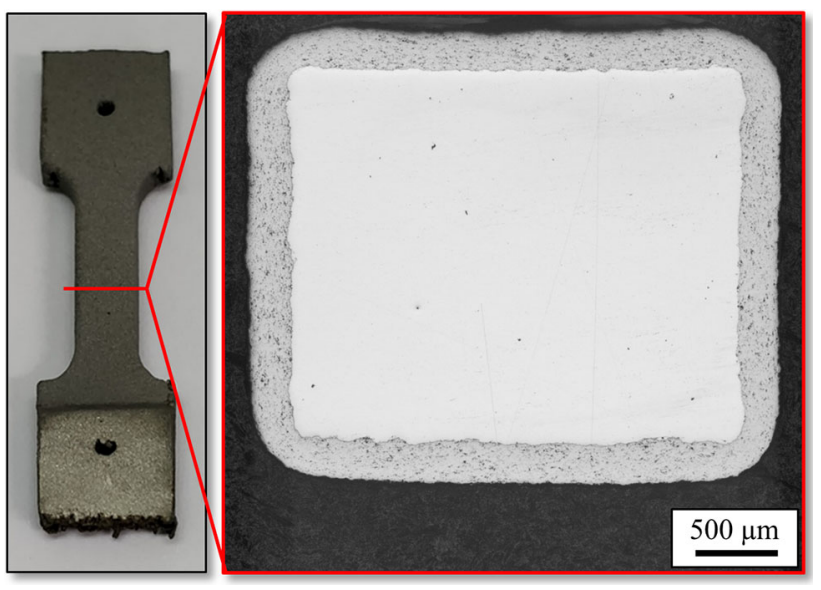

Fig. 6 Cross-sectional images taken by light microscopy showing the HVOF-sprayed WC-Co coating deposited onto a grit-blasted $316 \mathrm{~L}$ substrate (sample F100)

although the high kinetic energy of the HVOF process in combination with the hard particle-reinforced feedstock (i.e., 88 wt.\% of WC with a FSSS of $2.5 \mu \mathrm{m}$ ) should exert a peening effect. The impacts of the WC-Co particles, in this case, do not lead to a leveling of the surface asperities (i.e., protruding particles). Instead, the impinging spray particles lead to the formation of a rugged surface. This assumption is substantiated by comparing an uncoated and a coated substrate surface after grinding (i.e., the interface between the HVOF-sprayed WC-Co coating and the ground 316L substrates, see sample P2500, Fig. 8). Thus, the interface shows some concave peripheries, suggesting substrate deformation by the high kinetic energy of the WC-Co particles upon impact. When compared to the initial interface roughness (i.e., substrate surface roughness prior to the coating deposition), the cross-sectional analysis reveals a higher interface roughness after spraying. In this case, the coated substrate surface exhibits a mean roughness depth $\mathrm{Rz}$ of $5.71 \mu \mathrm{m}$ and a mean roughness $\mathrm{Ra}$ of $0.98 \mu \mathrm{m}$, whereas the uncoated substrate surface features a mean roughness depth $\mathrm{Rz}$ of $0.32 \mu \mathrm{m}$ and a mean roughness $\mathrm{Ra}$ of $0.05 \mu \mathrm{m}$. In addition, the effectiveness of the peening effect (i.e., caused by the impinging spray particles) cannot be clearly demonstrated as strain hardening effects are hardly evident. Table 7 shows the measured hardness values near the center of the sample $\left(H_{\mathrm{s}, \mathrm{center}}\right)$, and close to the coating-substrate interface $\left(H_{\mathrm{s}}\right)$ for the differently pre-treated $316 \mathrm{~L}$ substrates. To exclude a peening effect, a mechanically untreated sample can be considered below. In this respect, sample AS shows a $H_{\mathrm{s}, \mathrm{center}}$ of $2.98 \pm 0.01 \mathrm{GPa}$ near the center of the sample, whereas the subsurface area close to the interface demonstrates a $H_{\mathrm{s} \text {,interface }}$ of $3.10 \pm 0.02 \mathrm{GPa}$. Similar values were measured for sample AS/SRT $\left(H_{\mathrm{s}, \text { center }}=\right.$ $2.91 \pm 0.02 \mathrm{GPa} ; H_{\mathrm{s}, \text { interface }}$ of $\left.2.96 \pm 0.05 \mathrm{GPa}\right)$. In this 

taken by light microscopy showing the HVOF-sprayed WC-Co coating deposited onto the $316 \mathrm{~L}$ substrate in its as-built state after SLM (sample AS)
Fig. 7 Cross-sectional images
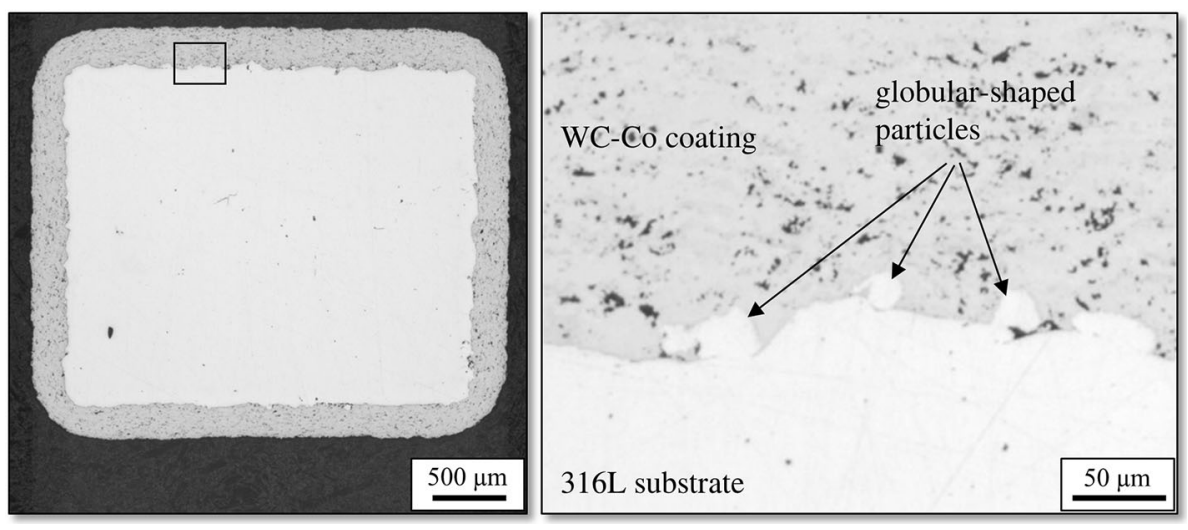

Fig. 8 Cross-sectional images taken by light microscopy showing (a) the uncoated and (b) the coated substrate surface after grinding of sample P2500
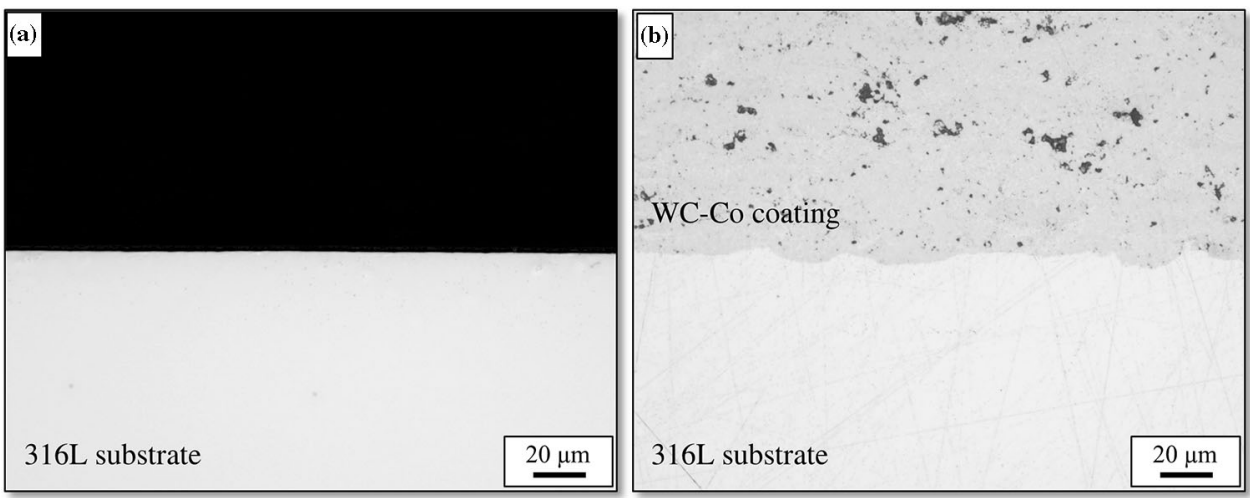

case, the SRT should not lead to any distinct change in hardness. As opposed to that, the differently grit-blasted $316 \mathrm{~L}$ substrates exhibit a higher hardness close to the interface when compared to the hardness near the center of the sample, suggesting the previously insertion of strain hardening effects due to surface deformation upon impact of the grit blasting particles. With regard to the ground $316 \mathrm{~L}$ substrates, a slight increase in hardness close to the coating-substrate interface is obtained from the nanoindentation experiments, but this is not significant.

Regarding the Vickers interfacial indentation tests with loads up to 294.21 N (HV30), none of the samples showed the appearance of cracks at the interface, implying a good bonding of the WC-Co coating on the differently pretreated $316 \mathrm{~L}$ substrates processed by SLM. For instance, Fig. 9(a) shows the residual indent (HV30) at the interface of sample F40, i.e., from a macroscopic view. With the use of an increased load of $490.35 \mathrm{~N}$ (HV50), cracks were generated and propagated at the interface (Fig. 9b). With further load increase such as $980.70 \mathrm{~N}$ (HV100), the residual indents were greatly enlarged (Fig. 9c). As a result, all the WC-Co coatings failed cohesively. According to Yamazaki et al. (Ref 41), the coating thickness should be at least three times larger than half of the diagonal of the residual indent in order to obtain adequate results. This postulate is not valid for the use of increased loads, in particular, for a load of $980.70 \mathrm{~N}$ (HV100).

Table 7 summarizes the crack lengths measured by Vickers interfacial indentation tests with a load of $490.35 \mathrm{~N}$ (HV50). The table also contains the values for $E_{\mathrm{s}}$, $E_{\mathrm{c}}, H_{\mathrm{s}}$, and $H_{\mathrm{c}}$ of the differently pre-treated $316 \mathrm{~L}$ substrates and individual WC-Co coatings determined through nanoindentation at the coating-substrate interface. From the obtained values, the interfacial indentation toughness $\mathrm{Kca}$ can be calculated, using Eq 1 and 2. Figure 10 shows the calculated values of $\mathrm{Kca}$ for the different coating-substrate systems depending on the substrate pre-treatment. The samples AS (Fig. 10a) and AS/SRT (Fig. 10b) show a Kca of $10.35 \mathrm{MPa} \mathrm{m}^{1 / 2}$, and $10.15 \mathrm{MPa} \mathrm{m}^{1 / 2}$, respectively, suggesting a reduced deviation of results for the given 316L substrates in their initial state. The roughness measurements (Table 5) as well as the residual stress measurements (Fig. 5) reveal a similar surface integrity for both substrates. Thus, significant differences in the interface morphology and the residual stresses at the interface can be precluded. Based on the Kca values, it can be concluded that the HVOF-sprayed WC-Co coating exhibits an adequate adhesion to the $316 \mathrm{~L}$ substrate in its as-built state processed by SLM. Comparable values for Kca with respect to different substrate coating material combinations, i.e., HVOF-sprayed hard coatings on various steel 
Table 7 Mechanical properties obtained from nanoindentation for the different coating-substrate systems depending on the substrate pretreatment

\begin{tabular}{|c|c|c|c|c|c|c|}
\hline \multirow[t]{3}{*}{ Sample } & \multicolumn{3}{|c|}{ 316L substrate } & \multicolumn{2}{|c|}{ WC-Co coating } & \multirow{3}{*}{$\begin{array}{c}\text { WC-Co coating/316L substrate (interface) } \\
\qquad a_{\mathrm{c}}, \mu \mathrm{m} \\
\text { Mean value (each Exp.) }\end{array}$} \\
\hline & $H_{\mathrm{s}, \text { center }}, \mathrm{GPa}$ & $E_{\mathrm{s}}, \mathrm{GPa}$ & $H_{\mathrm{s}}, \mathrm{GPa}$ & $E_{\mathrm{c}}, \mathrm{GPa}$ & $H_{\mathrm{c}}, \mathrm{GPa}$ & \\
\hline & \multicolumn{3}{|c|}{ Mean value (each Exp.) } & \multicolumn{2}{|c|}{ Mean value (each Exp.) } & \\
\hline \multirow[t]{3}{*}{ AS } & 2.96 & 181.41 & 3.09 & 311.93 & 14.29 & 284.65 \\
\hline & 2.98 & 185.59 & 3.09 & 322.33 & 14.42 & 274.70 \\
\hline & 2.99 & 185.05 & 3.13 & 328.21 & 15.26 & 294.53 \\
\hline \multirow[t]{3}{*}{$\mathrm{F} 40$} & 3.03 & 178.79 & 3.79 & 329.89 & 16.47 & 238.72 \\
\hline & 3.04 & 189.45 & 3.63 & 330.13 & 15.76 & 225.45 \\
\hline & 3.07 & 180.49 & 3.66 & 297.28 & 13.19 & 196.44 \\
\hline \multirow[t]{3}{*}{ F100 } & 3.10 & 186.89 & 3.54 & 319.36 & 14.74 & 271.64 \\
\hline & 3.03 & 178.45 & 3.66 & 301.32 & 14.85 & 255.27 \\
\hline & 3.05 & 185.61 & 3.68 & 310.83 & 14.98 & 305.46 \\
\hline \multirow[t]{3}{*}{$\mathrm{F} 240$} & 3.03 & 186.60 & 3.44 & 304.26 & 13.87 & 255.00 \\
\hline & 3.07 & 183.46 & 3.28 & 298.09 & 14.24 & 306.00 \\
\hline & 2.95 & 179.86 & 3.49 & 304.72 & 13.98 & 282.26 \\
\hline \multirow[t]{2}{*}{ P80 } & 2.93 & 187.90 & 3.10 & 318.19 & 14.44 & 310.86 \\
\hline & 3.15 & 182.00 & 3.40 & 311.04 & 15.61 & 332.96 \\
\hline \multirow[t]{3}{*}{ P600 } & 3.00 & 181.86 & 3.15 & 311.48 & 14.77 & 292.24 \\
\hline & 3.10 & 180.44 & 3.12 & 310.82 & 14.44 & 329.75 \\
\hline & 3.05 & 185.96 & 3.39 & 321.17 & 14.73 & 273.62 \\
\hline \multirow[t]{2}{*}{ P2500 } & 2.91 & 183.02 & 3.00 & 311.32 & 14.02 & 257.97 \\
\hline & 2.89 & 189.34 & 2.98 & 333.15 & 15.97 & 273.44 \\
\hline \multirow[t]{3}{*}{ AS/SRT } & 2.94 & 184.21 & 3.00 & 315.56 & 14.75 & 301.68 \\
\hline & 2.92 & 187.19 & 3.00 & 301.76 & 13.68 & 313.56 \\
\hline & 2.88 & 186.68 & 2.88 & 315.48 & 14.37 & 268.04 \\
\hline \multirow[t]{2}{*}{ F40/SRT } & 3.03 & 186.55 & 3.56 & 332.76 & 16.12 & 239.35 \\
\hline & 3.07 & 188.80 & 3.35 & 324.79 & 14.42 & 267.42 \\
\hline \multirow[t]{3}{*}{ F100/SRT } & 3.05 & 193.74 & 3.17 & 311.01 & 13.68 & 274.16 \\
\hline & 3.04 & 188.93 & 3.47 & 314.18 & 13.82 & 222.35 \\
\hline & 3.04 & 178.78 & 3.69 & 302.60 & 14.31 & 293.05 \\
\hline \multirow[t]{3}{*}{ F240/SRT } & 2.98 & 182.85 & 3.04 & 304.50 & 15.13 & 279.02 \\
\hline & 2.92 & 189.86 & 3.37 & 320.14 & 15.16 & 292.24 \\
\hline & 2.97 & 195.98 & 3.20 & 319.87 & 13.61 & 322.46 \\
\hline \multirow[t]{2}{*}{ P80/SRT } & 2.99 & 186.25 & 3.18 & 301.95 & 13.99 & 245.02 \\
\hline & 2.84 & 185.35 & 2.95 & 308.16 & 13.82 & 275.24 \\
\hline \multirow[t]{3}{*}{ P600/SRT } & 2.94 & 179.32 & 3.13 & 305.93 & 14.47 & 238.00 \\
\hline & 2.87 & 182.51 & 2.91 & 321.05 & 15.07 & 269.30 \\
\hline & 2.92 & 179.39 & 3.14 & 310.09 & 15.41 & 231.26 \\
\hline \multirow[t]{2}{*}{$\mathrm{P} 2500 / \mathrm{SRT}$} & 2.87 & 185.61 & 2.88 & 328.74 & 14.69 & 265.52 \\
\hline & 2.71 & 164.87 & 2.66 & 295.46 & 14.03 & 251.23 \\
\hline
\end{tabular}

substrates, are reported by Araujo et al. (Ref 21). For the grit-blasted 316L substrate surfaces, it is found that the use of a coarser grit blasting particle size (sample F40 versus F100, and F240) leads to an increased Kca (Fig. 10a). In contrast, for the ground $316 \mathrm{~L}$ substrate surfaces, the use of a coarser abrasive particle size (sample P80 versus P600, and P2500) results in a decreased Kca (Fig. 10a). A comparison of substrate surface roughness (Table 5) and calculated $\mathrm{Kca}$ suggests that the substrate surface roughness could therefore not be considered a determinant factor for the resulting coating adhesion within the given coatingsubstrate system. In contrast, comparing the data with the 

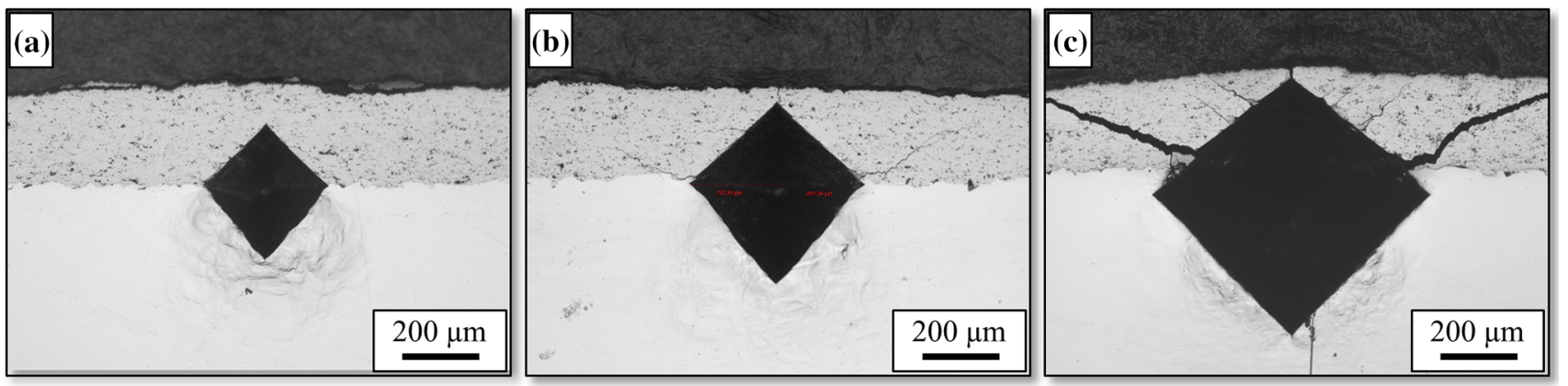

Fig. 9 Cross-sectional images taken by light microscopy showing the residual indent at the interface of sample F40 after Vickers interfacial indentation testing with different loads: (a) $294.21 \mathrm{~N}$ (HV30), (b) $490.35 \mathrm{~N}$ (HV50), and (c) $980.70 \mathrm{~N}$ (HV100)

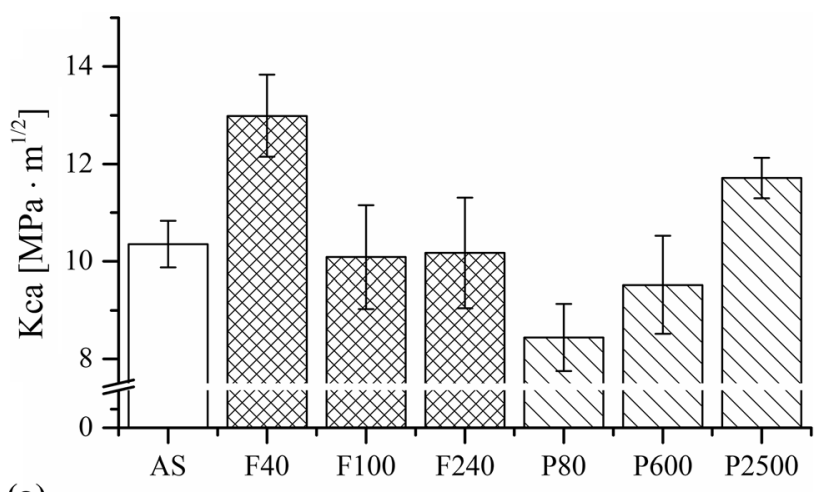

(a)

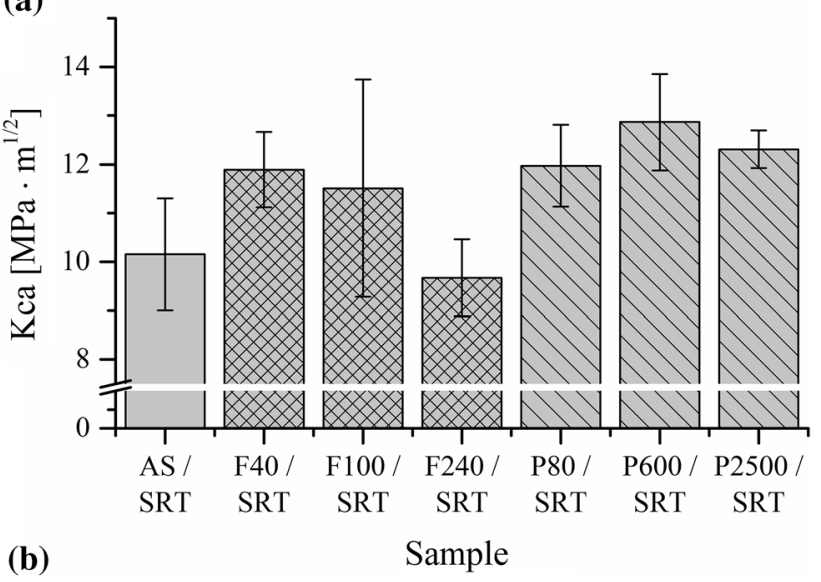

Fig. 10 Interfacial indentation toughness Kca determined by Vickers interfacial indentation tests (HV50) for various $316 \mathrm{~L}$ substrate surface conditions: (a) non-heat-treated 316L substrates, and (b) $316 \mathrm{~L}$ substrates processed by SRT

measured residual stresses (Fig. 5a) reveals the correlation that those samples with the highest residual stresses exhibit the lowest Kca (e.g., samples F100, F240, P80, and P600). This relationship is clearly visible for the ground $316 \mathrm{~L}$ substrate surfaces, especially, since all three sample types demonstrate a nearly identical surface roughness (Table 5). With regard to the Kca of the SRT samples (Fig. 10b), different observations have been made. Samples whose coating-substrate systems show an increased $K c a$ without prior SRT of the substrate also exhibit an increased $\mathrm{Kca}$ in the second measurement series whose substrates were subjected to a previous SRT (i.e., sample F40/SRT and P2500/SRT). For both samples, XRD analyses (Fig. 5b) point to reduced residual stresses in the substrate surface. In addition to the samples F40/SRT and P2500/SRT, however, it can be further noted that the samples F100/ SRT, P80/SRT, and P600/SRT demonstrate an increased $K c a$. Comparing the values of $K c a$ with the residual stress measurements (Fig. 5b) shows the correlation that a reduction in the residual stresses at the $316 \mathrm{~L}$ substrate surface leads to an increased $K c a$. Contrary to this trend, only sample F240/SRT exhibits a low $K c a$. The throughthickness residual stress profiles in the WC-Co coatings are not known. However, due to identical spray parameter settings in the sample preparation (i.e., coating deposition), it can be assumed that the contribution of residual stresses due to the HVOF spraying process is nearly constant in magnitude for the different samples. The fact that a reduction in the residual stresses in the substrate surface led to increased $\mathrm{Kca}$ values, it can be therefore assumed that the stress gradient at the interface between the HVOFsprayed WC-Co coating and the SLM 316L substrate essentially influences the coating adhesion.

It could be shown that the HVOF-sprayed WC-Co coatings predominantly exhibit sufficient adhesion to the differently pre-treated $316 \mathrm{~L}$ substrates processed by SLM. The inherent process characteristics of the HVOF process are of great importance. Due to the high kinetic energy of WC-Co particles upon impact on the additively manufactured substrate, the WC particles intrude into the substrate surface, contributing to a strong mechanical interlocking. Studying the interface fracture toughness in HVOF-sprayed WC-Co coatings on steel substrates, Watanabe et al. (Ref 42) confirmed that the compression and densification of the surrounding microstructure by the impact of WC particles as well as the intrusion of WC particles into the substrate are decisive factors for increasing the coating adhesion. Nevertheless, it is striking that improved coating adhesion 
is observed for the ground $316 \mathrm{~L}$ substrate surfaces, especially in combination with a prior SRT. It is assumed that this is caused by several effects: (1) removal of unmelted particles at the SLM substrate surface; (2) reduced risk of particle entrapment compared to grit-blasted SLM substrate surfaces; (3) reduced residual stresses at the SLM substrate surface due to SRT.

Nonetheless, in terms of the Vickers interfacial indentation tests, several constraints need to be taken into account to get reliable results. With respect to the image analysis, an accurate determination of the crack length is difficult to accomplish in practice. The presence of impurities or residues (e.g., abrasive particles) as well as the interface roughness itself can hinder the optical observation of cracks at the interface, which lead to a limited use. Moreover, there is a great risk that cracks partially pass through the coating or subareas of the coating, instead of propagating at the interface, precluding a precise measurement. In this context, the evidence of crack formation at the interface between the intruded WC particles and the 316L substrate need to be evaluated by high-resolution optical measurements. In the event that the crack formation predominantly occurs in the WC-Co coating, the interfacial indentation toughness is greater than the fracture toughness of the WC-Co coating. Therefore, the actual failure would be determined by the fracture toughness of the coating around the interface.

\section{Conclusion}

316L substrates processed by SLM were subjected to different pre-treatment procedures prior a subsequent WC-Co coating deposition by means of HVOF spraying. The substrate surface characteristics (i.e., surface roughness and residual stresses) were determined depending on the different pre-treatments, and their effect on the resulting coating adhesion was analyzed. With regard to the findings obtained from Vickers interfacial indentation tests, the influence of the mechanical pre-treatment or SRT on the resulting coating adhesion was not clearly apparent from the test results, since distinct differences were hardly discernible. Nevertheless, the results revealed some minor interactions. In general, the findings indicated that the HVOF-sprayed WC-Co coatings predominantly show good adhesion to the differently pre-treated $316 \mathrm{~L}$ substrates processed by SLM. Due to the high kinetic energy of WCCo particles upon impact on the 316L substrate, the WC particles intrude into the substrate surface, contributing to a strong mechanical interlocking. For the given coatingsubstrate system, it was found that the substrate surface roughness could not be considered a determinant factor for the resulting coating adhesion. Instead, it is rather obvious that the stress gradient at the interface between the HVOFsprayed WC-Co coating and the SLM 316L substrate essentially affects the coating adhesion. Accordingly, reduced residual stresses in the substrate surface (in this case by appropriate mechanical pre-treatment, or SRT) led to an increased coating adhesion.

Acknowledgments Open Access funding provided by Projekt DEAL. The authors gratefully thank the German Research Foundation (DFG) for the financial support. This work results from the project (TI343/130-1, SCHA1484/35-1).

Open Access This article is licensed under a Creative Commons Attribution 4.0 International License, which permits use, sharing, adaptation, distribution and reproduction in any medium or format, as long as you give appropriate credit to the original author(s) and the source, provide a link to the Creative Commons licence, and indicate if changes were made. The images or other third party material in this article are included in the article's Creative Commons licence, unless indicated otherwise in a credit line to the material. If material is not included in the article's Creative Commons licence and your intended use is not permitted by statutory regulation or exceeds the permitted use, you will need to obtain permission directly from the copyright holder. To view a copy of this licence, visit http://creativecommons. org/licenses/by/4.0/.

\section{References}

1. I. Gibson, D. Rosen, and B. Stucker, Additive Manufacturing Technologies: 3D Printing, Rapid Prototyping and Direct Digital Manufacturing. Springer, Berlin, 2015

2. J.-P. Kruth, M. Badrossamay, E.Yasa, J. Deckers, L. Thijs, J. Van Humbeeck, Part and Material Properties in Selective Laser Melting of Metals, in Proceedings of the 16th International Symposium on Electromachining, Shanghai, China, p. 1-12 (2010)

3. Y. Liu, Y. Yang, and D. Wang, A Study on the Residual Stress During Selective Laser Melting (Slm) of Metallic Powder, Int. J. Adv. Manuf. Technol., 2016, 87(1-4), p 647-656

4. SLM-Solutions, Fe-Basislegierung 316L (1.4404). https://slmsolutions.com/de/produkte/zubehoer-verbrauchsmaterialien/slmrmetallpulver/. Accessed 31 Jan 2019

5. Finetubes, Legierung 316L. http://www.finetubes.de/produkte/ materialien/edelstahlrohre/legierung-3161-uns-s31603-wnr-1. 4404/. Accessed 31 Jan 2019

6. B. Kocabekir, R. Kaçar, S. Gündüz, and F. Hayat, An Effect of Heat Input, Weld Atmosphere and Weld Cooling Conditions on the Resistance Spot Weldability of 316L Austenitic Stainless Steel, J. Mater. Process. Technol., 2008, 195(1-3), p 327-335

7. J. Suryawanshi, K.G. Prashanth, and U. Ramamurty, Mechanical Behavior of Selective Laser Melted 316L Stainless Steel, Mater. Sci. Eng. A, 2017, 696, p 113-121

8. M.S. Pham, B. Dovgyy, and P.A. Hooper, Twinning Induced Plasticity in Austenitic Stainless Steel 316L Made by Additive Manufacturing, Mater. Sci. Eng. A, 2017, 704, p 102-111

9. T. Simson, A. Emmel, A. Dwars, and J. Böhm, Residual Stress Measurements on Aisi 316L Samples Manufactured by Selective Laser Melting, Addit. Manuf., 2017, 17, p 183-189

10. C. Li, Z.Y. Liu, X.Y. Fang, and Y.B. Guo, Residual Stress in Metal Additive Manufacturing, Procedia CIRP, 2018, 71, p 348353 
11. P. Mercelis and J.-P. Kruth, Residual Stresses in Selective Laser Sintering and Selective Laser Melting, Rapid Prototyp. J., 2006, 12(5), p 254-265

12. A. Riemer, S. Leuders, M. Thöne, H.A. Richard, T. Tröster, and T. Niendorf, On the Fatigue Crack Growth Behavior in $316 \mathrm{~L}$ Stainless Steel Manufactured by Selective Laser Melting, Eng. Fract. Mech., 2014, 120, p 15-25

13. D. Herzog, V. Seyda, E. Wycisk, and C. Emmelmann, Additive Manufacturing of Metals, Acta Mater., 2016, 117, p 371-392

14. L. Löber, C. Flache, R. Petters, U. Kühn, and J. Eckert, Comparison of Different Post Processing Technologies for SLM Generated 316L Steel Parts, Rapid Prototyp. J., 2013, 19(3), p 173-179

15. M. Schmid and G.N. Levy, Finishing and coating von SLS-Teilen für Additive Manufacturing (AM) (in de), RTejournal - Forum für Rapid Technologie 7 (2010)

16. W. Tillmann, C. Schaak, J. Nellesen, M. Schaper, M.E. Aydinöz, and T. Niendorf, Functional Encapsulation of Laser Melted Inconel 718 By Arc-Pvd and Hvof For Post Compacting by Hot Isostatic Pressing, Powder Metall., 2015, 58(4), p 259-264

17. W. Tillmann, L. Hagen, C. Schaak, R. Zielke, M. Schaper, M. E. Aydinöz, Pretreatment and Coatability of Additive Manufactured Components Made by Means of Selective Laser Melting, in Proceedings of the International Thermal Spray Conference, ITSC2018, Ed., 2018, p 581-588 (2018)

18. B. Zhang, L. Zhu, H. Liao, and C. Coddet, Improvement of Surface Properties of Slm Parts by Atmospheric Plasma Spraying Coating, Appl. Surf. Sci., 2012, 263, p 777-782

19. U. Selvadurai, P. Hollingsworth, I. Baumann, B. Hussong, W. Tillmann, S. Rausch, and D. Biermann, Influence of the Handling Parameters on Residual Stresses of Hvof-Sprayed Wc-12Co Coatings, Surf. Coat. Technol., 2015, 268, p 30-35

20. Y.Y. Santana, P.O. Renault, M. Sebastiani, J.G. La Barbera, J. Lesage, E. Bemporad, E. Le Bourhis, E.S. Puchi-Cabrera, and M.H. Staia, Characterization and Residual Stresses of WC-Co Thermally Sprayed Coatings, Surf. Coat. Technol., 2008, 202(18), p 4560-4565

21. P. Araujo, D. Chicot, M. Staia, and J. Lesage, Residual Stresses and Adhesion of Thermal Spray Coatings, Surf. Eng., 2005, 21(1), p 35-40

22. Y.-Y. Wang, C.-J. Li, and A. Ohmori, Influence of Substrate Roughness on the Bonding Mechanisms of High Velocity OxyFuel Sprayed Coatings, Thin Solid Films, 2005, 485(1-2), p 141147

23. K. Tosha and K. IIda, Residual Stress on the Grit Blasted Surface. Met. Behav. Surf. Eng. 323-328 (1989)

24. K. Poorna Chander, M. Vashista, K. Sabiruddin, S. Paul, and P.P. Bandyopadhyay, Effects of Grit Blasting on Surface Properties of Steel Substrates, Mater. Des., 2009, 30(8), p 2895-2902

25. Federation of European Producers of Abrasives, Fepa Grains Standards. https://www.fepa-abrasives.com/abrasive-products/ grains. Accessed 15 Nov 2019

26. I.C. Noyan and J.B. Cohen, Residual Stress, Springer, New York, 1987

27. V. Hauk and H. Behnken, Structural and Residual Stress Analysis by Nondestructive Methods: Evaluation-application-assessment, Elsevier, Amsterdam, 2006
28. B. Eigenmann and E. Macherauch, Röntgenographische Untersuchung Von Spannungszuständen in Werkstoffen, Mat.-wiss. $u$. Werkstofftech., 1995, 26(3), p 148-160

29. D. Chicot, P. Araujo, N. Horny, A. Tricoteaux, and J. Lesage, Application of the Interfacial Indentation Test for Adhesion Toughness Determination, Surf. Coat. Technol., 2005, 200(1-4), p $174-177$

30. G. Marot, J. Lesage, P. Démarécaux, M. Hadad, and M.H. Staia, Interfacial Indentation and Shear Tests to Determine the Adhesion of Thermal Spray Coatings, Surf. Coat. Technol., 2006, 201(5), p 2080-2085

31. G. Marot, P. Démarécaux, J. Lesage, M. Hadad, and M.H. Staia, The interfacial indentation test to determine adhesion and residual stresses in NiCr VPS coatings, Surf. Coat. Technol., 2008, 202(18), p 4411-4416

32. P. Demarecaux, D. Chicot, and J. Lesage, Interface Indentation Test for the Determination of Adhesive Properties of Thermal Sprayed Coatings, J. Mater. Sci. Lett., 1996, 15(16), p 1377-1380

33. M.H. Staia, E. Ramos, A. Carrasquero, A. Roman, J. Lesage, D. Chicot, and G. Mesmacque, Effect of Substrate Roughness Induced by Grit Blasting Upon Adhesion of WC-17\% Co Thermal Sprayed Coatings, Thin Solid Films, 2000, 377-378, p $657-$ 664

34. J. Lesage and D. Chicot, Role of Residual Stresses on Interface Toughness of Thermally Sprayed Coatings, Thin Solid Films, 2002, 415(1-2), p 143-150

35. W.C. Oliver and G.M. Pharr, An Improved Technique for Determining Hardness and Elastic Modulus Using Load and Displacement Sensing Indentation Experiments, J. Mater. Res., 1992, 7(06), p 1564-1583

36. E. Liverani, S. Toschi, L. Ceschini, and A. Fortunato, Effect of Selective Laser Melting (Slm) Process Parameters on Microstructure and Mechanical Properties of 316L Austenitic Stainless Steel, J. Mater. Process. Technol., 2017, 249, p 255-263

37. K. Saeidi, X. Gao, Y. Zhong, and Z.J. Shen, Hardened Austenite Steel With Columnar Sub-Grain Structure Formed by Laser Melting, Mater. Sci. Eng. A, 2015, 625, p 221-229

38. Z. Sun, X. Tan, S.B. Tor, and W.Y. Yeong, Selective Laser Melting of Stainless Steel 316L With Low Porosity and High Build Rates, Mater. Des., 2016, 104, p 197-204

39. M. Mellali, A. Grimaud, A.C. Leger, P. Fauchais, and J. Lu, Alumina Grit Blasting Parameters For Surface Preparation in the Plasma Spraying Operation, J. Therm. Spray Technol., 1997, 6(2), p 217-227

40. B. Denkena and H.K. Tönshoff, Spanen, Springer, Berlin, 2011

41. Y. Yamazaki, M. Arai, Y. Miyashita, H. Waki, and M. Suzuki, Determination of Interfacial Fracture Toughness of Thermal Spray Coatings by Indentation, J. Therm. Spray Technol., 2013, 22(8), p 1358-1365

42. M. Watanabe, A. Owada, S. Kuroda, and Y. Gotoh, Effect of WC Size on Interface Fracture Toughness of WC-Co HVOF Sprayed Coatings, Surf. Coat. Technol., 2006, 201(3-4), p 619-627

Publisher's Note Springer Nature remains neutral with regard to jurisdictional claims in published maps and institutional affiliations. 